\title{
Fruits and vegetables intake and characteristics associated among adolescents from Southern Brazil
}

Marta A Rieth', Marina B Moreira ${ }^{1,2}$, Flávio D Fuchs²,3, Leila B Moreira ${ }^{2,3}$ and Sandra C Fuchs ${ }^{2,3,4^{*}}$

\begin{abstract}
Background: Increased body weight has been associated with an unhealthy diet, low consumption of fruits and vegetables. Our objective was to investigate whether adolescents had low intake of fruits and vegetables, and whether gender, age and education could affect the feeding patterns.

Methods: A population-based sample of adolescents, aged 12-19 years, were randomly selected in southern Brazil and included in this cross-sectional study. The total daily consumption of fruits, vegetables, rice and beans were investigated in standardized household interviews, using a food frequency questionnaire and questions, being categorized as five or more servings per day as the five-a-day diet. ANOVA, ANCOVA, and modified Poisson regression were used in the analysis.

Results: Adolescents ( $n=568$ ) were included, $49.5 \%$ boys, $14.3 \%$ had overweight and $8.8 \%$ obesity. Approximately $23 \%$ of participants consumed five daily servings of fruits and vegetables. It was observed that $36.7 \%$ of boys and $31.0 \%$ of girls consumed less than one serving of fruit per day, and $58.4 \%$ and $44.6 \%$, respectively, consumed less than one serving of vegetables. The consumption of vegetables, fruits, and rice and beans were not independently associated with gender. Overweight was associated with higher intake of five-a-day, independently of confounding factors.
\end{abstract}

Conclusions: Adolescents from southern Brazil have lower frequency of consumption of five servings a day of fruits and vegetables combined.

Keywords: Adolescents, Fruits, Vegetables, Five-a-day, Dietary pattern, Diet

\section{Background}

In recent decades, excessive weight gain surpassed malnutrition in adolescents worldwide [1,2]. Since the late 1970s [3], the increasing trend of overweight seems to have reached a state of equilibrium among American adolescents [4], which was similar to the observed in Brazil [5].

Several components of the diet have been investigated as determinants of the body weight gain in adolescents,

\footnotetext{
* Correspondence: scfuchs@terra.com.br

${ }^{2}$ Postgraduate Studies Program in Cardiology, School of Medicine, Universidade Federal do Rio Grande do Sul, Ramiro Barcelos 2600, CEP 90035-003, Porto Alegre, RS, Brazil

${ }^{3}$ Division of Cardiology, and the National Institute for Science and Technology for Health Technology Assessment (IATS/CNPq), Hospital de Clínicas de Porto Alegre, Ramiro Barcelos 2350, Centro de Pesquisa Clínica, Cardiolab-Hipertensão, CEP 90035-003, Porto Alegre, RS, Brazil

Full list of author information is available at the end of the article
}

including few fruits and vegetables [6], high-calorie foods [7], energetic drinks [6,8], and meals outside of the home [9]. Inadequate fruits and vegetables intake has been associated with male gender [10], increases with age $[10,11]$, smoking [12], alcoholic beverages consumption [10], and sedentary lifestyle [13]. In addition, a direct association was detected between socioeconomic level and healthy dietary habits $[10,13,14]$, which could influence behavioral interventions to increase fruit and vegetable intake $[15,16]$.

The five-a-day program, initiated in the United States [17] and implemented in several countries, was created to promote fruit and vegetable consumption and augment people's exposure in order to revert the increase of obesity-related diseases. The intake of at least five servings of fruits and vegetables a day has been recommended to

\section{Biomed Central}


reach this goal. The worldwide spread of this program led to adaptations of the main messages and some of them provide further recommendations for specific populations such as adolescents [18]. In addition, varying the colors of fruits and vegetables is more likely that adequate intake of vitamins and other nutrients is achieved [19].

However, there is a weak linkage of fruits and vegetables intake with adiposity indexes among adults [20] and it was not assessed for adolescents. We postulate that demographic and socioeconomic characteristics are some of the determinants of intake. The aim of this study was to assess the intake of fruits, vegetables and five-a-day and their association with socio-demographic characteristics among adolescents in southern Brazil.

\section{Material and methods}

\section{Study design and population}

A cross-sectional study was conducted on a populationbased sample of adolescent boys and girls 12 to 19 years-old living in the city of Porto Alegre, southern Brazil, in 2007. The city has over 1,300,000 inhabitants and the economy is based on the third sector. Participants were selected at random through a multi-stage probability sampling based on 106 of the 2,157 census sectors (geographical subdivisions of the city, as defined by the Brazilian Institute of Geography and Statistics) [5], followed by a simple random sampling of one block in each tract, and a systematic sampling of the households from each block. All adolescents living at the eligible households were sampled. Weighting of households and effect of design were taking into account in the analysis of the data. It was used the complex sample module, of the Statistical Program for Social Sciences version 17.0 (SPSS Inc., Chicago, USA).

The sample size needed to detect a difference of one serving of fruits and vegetables a day between boys and girls in the ratio of 1:1, with 95\% confidence interval and power of $80 \%$, was estimated in 568 adolescent participants for dietary analysis. The Institution Review Board, which is accredited by the US Office of Human Research Protections, approved the protocol and participants and their legal guardians signed a consent form to participate.

\section{Studied variables}

Subjects were interviewed at the households using standardized questionnaire regarding demographic data, lifestyle characteristics, and dietary habits. Education (years at school), smoking status (current smokers defined as $\geq 1$ cigarettes/week for those who had smoked $\geq 100$ cigarettes during lifetime) [21], and alcoholic beverage consumption (amount and type of alcoholic drinks consumed in the last 30 days, in order to estimate the ethanol consumed weekly [22]) were assessed. The analysis was conducted with sample stratification at the $75^{\text {th }}$ percentile, designating a group as having greater alcohol consumption ( $\geq 12.7$ grams of ethanol/week). International Physical Activity Questionnaire (IPAQ) was used to estimate time spent in walking and all moderate-to-vigorous physical activities in the seven days prior to the interview, considering sessions that lasted over 10 minutes [23].

The interviewers were trained and a standardized questionnaire was used to collect data. Anthropometric measurements were made in duplicate, carried out with adolescents wearing light clothing and barefoot. Measurements were carried out for weight (in kilograms), measured to the nearest $100 \mathrm{~g}$ with a scale $\left(\right.$ Plenna ${ }^{\circledR}$ scale, model TINN 00088 Plenna - SA, São Paulo, Brazil) and height (in centimeters) to an accuracy of $0.5 \mathrm{~cm}$. Body mass index (BMI) was computed as weight/height ${ }^{2}$ $\left(\mathrm{kg} / \mathrm{m}^{2}\right)$ and underweight and overweight were defined according to Cole et al. using correspondent values of BMI for children and adolescents in relation to adults cut-offs points [24]. Criteria for underweight and overweight (including obesity) for adolescents were based on the percentile curves constructed using the LMS (lambda, mu, sigma) method [25], from a curve passing through each adult cut-off point of $<18.5$ and $\geq 25.0 \mathrm{~kg} / \mathrm{m}^{2}$, respectively, at age of 18 years $[24,26]$.

\section{Diet evaluation}

Details on the development and validation of the food frequency questionnaire (FFQ) were described elsewhere [27]. Briefly, the list generated to select food items that should be part of the FFQ were identified through $24 \mathrm{~h}$ dietary recall, filled by 61 adolescents selected at schools and universities in the city and in the Metropolitan area. This list was compared to that obtained in a populationbased study, conducted in another city in southeastern of Brazil. The lists were similar, but 14 food items were dropped and 64 were added retaining those food items consumed by at least $5 \%$ of adolescents, in addition to food items that represent the influence of German, Italian, Japanese, and southern Brazilian cuisine. This food list was retested and additional changes were made. The FFQ inquired about the frequency and amount of consumption of 135 items, recording amount, frequency, periodicity (daily rate, weekly, monthly, or annual), and number of months in the past year each item was consumed. Each dietary item was transformed in daily ingestion (grams), and nutrients and total energy were calculated through Support to Nutrition (NUTWIN) software, developed by the Center of Computer Science in Health of Federal University of São Paulo (UNIFESP). Diets with energy intake inferior to $500 \mathrm{kcal}$ or superior to $5000 \mathrm{kcal}$ were considered unlikely and excluded from this analysis. In a random sample of 127 adolescents we validated the FFQ with the average of two 24 hours 
recalls, obtaining an attenuated correlation of 0.52 for calories [27]. The FFQ also investigated the intake of cooked items, as rice and beans, as major sources of carbohydrate and energy. The portion sizes were estimated using small, medium, and large serving spoons as a reference. Black beans are the main type of beans consumed in southern Brazil.

The questionnaire investigated cropped vegetables, defined as leaves, fruits, stems, seeds, tubers and roots used for human consumption, as a whole or in part, including: lettuce, watercress, broccoli, cauliflower, spinach, cabbage, arugula, parsley and celery, carrots, beets, zucchini, squash, cucumber, onion, and others. Fruits were identified as the pulp surrounding the plant seeds and having juice, flavor, and tastes sweet, such as: orange, bergamot, banana, apple, lemon, papaya, grapes, mango, and many others [28].

Daily intake of fruits and vegetables, in grams, was categorized on standardized servings, such as 1 medium sized fruit, $1 / 2$ cup of fruits, $1 / 4$ cup of dried fruits, or 1 cup of leafy vegetables. The total of servings was computed for fruits and vegetables. The overall consumption of fruits and vegetables was categorized into five-a-day based on intake of at least five servings a day. Rice and beans, grain and fiber components were also measured by servings a day. The interviewers were trained and a standardized questionnaire was used to collect the data. Certification of the interviewers was made in loco for approximately $10 \%$ of the sampling, and additional $10 \%$ of the interviews were repeated for quality control.

\section{Statistical analysis}

Data were entered into the Epinfo software database (Epi Info ${ }^{\circledR}$, version 3.2.2, Atlanta, GA, USA, 2005) and checked for consistency of data entry by double entry. Crude analysis was performed using Pearson's chisquare test (categorical variables), and analysis of variance (ANOVA) (continuous variables). Data were stratified or adjusted by gender and other confounding variables - age, education, smoking, alcoholic beverage consumption, and physical activity - in the multivariate analysis, by analysis of covariance, using the Complex samples module of the Statistical Package for Social Sciences $\left(\right.$ SPSS $^{\circledR}$, version 16, Chicago, Illinois, USA).

\section{Results}

In the total, 568 adolescents, out of 607 , aged 12 to 14 $(\mathrm{n}=199), 15$ to $17(\mathrm{n}=232)$, and 18 to 19 years-old $(\mathrm{n}=$ 137), $49.5 \%$ males, and $50 \%$ white skin color were evaluated. Thirty six adolescents from 28 households declined to participate, so $94 \%$ of the eligible adolescents were enrolled. Table 1 shows that boys and girls were similar regarding age distribution, skin color, education, and smoking. However, there were different patterns of
Table 1 Characteristics of adolescents from 12 to 19 years of age enrolled in SOFT study, in southern Brazil [N (\%) or mean \pm SD]

\begin{tabular}{|c|c|c|c|c|}
\hline & $\begin{array}{l}\text { Total } \\
\mathrm{N}=568\end{array}$ & $\begin{array}{l}\text { Boys } \\
N=281\end{array}$ & $\begin{array}{l}\text { Girls } \\
N=287\end{array}$ & P value* \\
\hline Age (years) & & & & 0.8 \\
\hline $12-14$ & 199 (35.0) & $102(36.2)$ & 97 (33.8) & \\
\hline $15-17$ & $232(40.8)$ & $111(39.5)$ & $121(42.2)$ & \\
\hline 18-19 & $137(24.1)$ & $68(24.2)$ & $69(24.0)$ & \\
\hline White skin color & $284(50.0)$ & $132(47.0)$ & $152(53.0)$ & 0.15 \\
\hline Education (years) & $7.5 \pm 2.5$ & $7.5 \pm 2.6$ & $7.6 \pm 2.5$ & 0.8 \\
\hline Current smokers & $57(10.0)$ & $23(8.2)$ & $34(11.8)$ & 0.15 \\
\hline $\begin{array}{l}\text { Alcohol consumption } \\
\text { in the last } 30 \text { days } \\
(\mathrm{g} / \text { week })^{\dagger}\end{array}$ & & & & 0.008 \\
\hline No & $357(62.9)$ & $184(65.5)$ & $173(60.3)$ & \\
\hline$<12.7$ & $69(12.1)$ & $22(7.8)$ & $47(16.4)$ & \\
\hline$\geq 12.7$ & $142(25.0)$ & $75(26.7)$ & $67(23.3)$ & \\
\hline Physical activity & & & & $<0.001$ \\
\hline Mild & $139(24.5)$ & $57(20.3)$ & $82(28.6)$ & \\
\hline Moderate & $269(47.4)$ & $115(40.9)$ & $154(53.7)$ & \\
\hline Vigorous & $160(28.2)$ & 109 (38.8) & $51(17.8)$ & \\
\hline Body mass index** & & & & 0.001 \\
\hline Underweight & $45(7.9)$ & $11(3.9)$ & $34(11.8)$ & \\
\hline Normal & $392(69.0)$ & $196(69.8)$ & $196(68.3)$ & \\
\hline Overweight & $131(23.1)$ & $74(26.3)$ & 57 (19.9) & \\
\hline
\end{tabular}

* Pearson chi-squared test.

${ }^{+}$Grams of ethanol per week.

** BMI categorized as proposed by Cole et al.

alcohol consumption, physical activity, and BMI between boys and girls. Underweight was more prevalent among girls and overweight among boys. To further explore this association, we run the analysis stratified by age, and the association between BMI and gender was statistically significant only among adolescents aged 18 to 19 years.

The overall consumption of fruits was less than three servings a day for most of adolescents (Table 2), similar among boys and girls. The intake of at least three servings a day of vegetables was below $10 \%$, half of the adolescents reported less than one serving a day, but it was more prevalent for boys than girls. There was no difference in the intake of five-a-day between boys and girls. The majority of boys consumed three or more servings a day of rice and beans, versus only a third of girls.

Table 3 shows that education, smoking and BMI were not associated with intake of fruits and vegetables. However, education was inversely associated whereas physical activity directly related to the consumption of rice and beans. Vigorous physical activity can probably explain the consumption of fruits per day, which could have contributed to five days. Body mass index was associated with five-a-day. 
Table 2 Daily consumption of fruits and vegetables by adolescents enrolled in, SOFT study [N (\%)]

\begin{tabular}{lllll}
\hline & Total & $\begin{array}{l}\text { Boys } \\
(\mathbf{N}=\mathbf{2 8 1})\end{array}$ & $\begin{array}{l}\text { Girls } \\
\mathbf{( N = 2 8 7 )}\end{array}$ & P value $^{*}$ \\
\hline Fruits (servings/d) & & & 0.2 \\
\hline$<1$ & $192(33.8)$ & $103(36.7)$ & $89(31.0)$ & \\
\hline $1-1.9$ & $152(26.8)$ & $67(23.8)$ & $85(29.6)$ & \\
\hline $2-2.9$ & $83(14.6)$ & $37(13.2)$ & $46(16.0)$ & \\
\hline$\geq 3$ & $141(24.8)$ & $74(26.3)$ & $67(23.3)$ & \\
\hline Vegetables (servings/d) & & & 0.009 \\
\hline$<1$ & $292(51.4)$ & $164(58.4)$ & $128(44.6)$ & \\
\hline $1-1.9$ & $149(26.2)$ & $64(22.8)$ & $85(29.6)$ & \\
\hline $2-2.9$ & $73(12.9)$ & $28(10.0)$ & $45(15.7)$ & \\
\hline$\geq 3$ & $54(9.5)$ & $25(8.9)$ & $29(10.1)$ & \\
\hline Five-a-day ${ }^{\dagger}$ & $129(22.7)$ & $67(23.8)$ & $62(21.6)$ & 0.5 \\
\hline Rice and beans (servings/d) & & & $<0.001$ \\
\hline$<1$ & $67(11.8)$ & $16(5.7)$ & $51(17.8)$ & \\
\hline $1-1.9$ & $144(25.4)$ & $49(17.4)$ & $95(33.1)$ & \\
\hline $2-2.9$ & $109(19.2)$ & $57(20.3)$ & $52(18.1)$ & \\
\hline$\geq 3$ & $248(43.7)$ & $159(56.6)$ & $89(31.0)$ & \\
\hline
\end{tabular}

* Pearson chi-squared test.

† Consumption of five servings a day.

Figure 1 shows that boys were more likely to consume higher number of servings a day of rice and bean than girls, independently of age, education, and physical activity. However, there was no association of gender with fruits and vegetables, even after the control for confounding factors.

Figure 2 demonstrates that independently of age, sex, alcohol consumption, and physical activity, adolescents who had overweight had a 1.4 prevalence of five-a-day intake in comparison to those with normal BMI.

\section{Discussion}

This population-based survey carried out on adolescents has detected low frequency of fruits, vegetables, and five-a-day intake. Among several characteristics only overweight was associated with increased intake of fivea-day, regardless of age range, male sex, vigorous physical activity, and higher alcohol consumption. Even though, individually fruits and vegetables were not associated. Rice and beans have been consumed daily by most of the adolescents, and boys had more servings a day than girls, independently of confounding factors.

The overall five-a-day intake was lower than the reported for the American adolescents in the study EAT (Eating Among Teens), which showed that approximately a third reached the servings recommended [29]. In contrast, among middle and upper class adolescents, from private schools from Venezuela, $74 \%$ had five or more servings of fruits and $42 \%$ more than five portions of green vegetables per day [30]. On the other side, this pattern of fiber and grain consumption - typical of the Brazilian diet [31] - corroborated previous results from a population-based study in adolescents from southern Brazil [32]. However, black beans and rice were not associated with BMI, as it has been reported for adults [27].

The recommendations of the five-a-day program in Brazil have not been advertised as it was in some developed countries [33]. Information aiming the adolescent population should be provided including items belonging to the five-a-day program. White rice is an important source of energy, similar to the potato in other countries, and should be part of the dietary health plan as well as beans.

The higher prevalence of obesity among boys was different of previous studies [34,35]. Considering that the sub-analysis of BMI by gender was detected on adolescents aged 18 to 19 years, a potential explanation could be higher muscular development of boys than girls. This finding could not be discriminated by BMI that does not differentiate lean mass from fat mass.

Table 3 Characteristics associated with fruits and vegetables consumed per day among adolescents from Southern Brazil [mean \pm SD $]^{\ddagger}$ or $n(\%)^{\neq \neq}$

\begin{tabular}{|c|c|c|c|c|}
\hline & Fruits & Vegetables & Five-a-day & Rice $\&$ beans \\
\hline \multicolumn{5}{|c|}{ Education (years) } \\
\hline $0-4$ & $1.9 \pm 2.1$ & $1.4 \pm 2.0$ & $11(16.9)$ & $4.2 \pm 2.6$ \\
\hline $5-8$ & $2.2 \pm 2.0$ & $1.3 \pm 1.3$ & $70(23.8)$ & $3.5 \pm 2.4$ \\
\hline$\geq 9$ & $2.2 \pm 2.3$ & $1.4 \pm 1.4$ & $48(23.0)$ & $2.8 \pm 0.2$ \\
\hline$P$ value & 0.5 & 0.8 & 0.5 & $<0.001$ \\
\hline \multicolumn{5}{|c|}{ Current smoker } \\
\hline $\mathrm{No}$ & $2.2 \pm 2.1$ & $1.3 \pm 1.4$ & $114(22.3)$ & $3.3 \pm 2.5$ \\
\hline Yes & $2.6 \pm 2.7$ & $1.6 \pm 1.5$ & $15(26.3)$ & $3.6 \pm 2.2$ \\
\hline$P$ value & 0.2 & 0.2 & 0.5 & 0.5 \\
\hline \multicolumn{5}{|c|}{ Alcohol consumption in the last 30 days $\left(\mathrm{g} /\right.$ week) ${ }^{\mathrm{f}}$} \\
\hline No & $2.1 \pm 2.0$ & $1.3 \pm 1.4$ & $74(20.7)$ & $3.4 \pm 2.6$ \\
\hline$<12.7$ & $2.6 \pm 2.5$ & $1.3 \pm 1.1$ & $20(29.0)$ & $2.9 \pm 2.0$ \\
\hline$\geq 12.7$ & $2.3 \pm 2.4$ & $1.6 \pm 1.7$ & $35(24.6)$ & $3.4 \pm 2.2$ \\
\hline$P$ value & 0.09 & 0.06 & 0.3 & 0.4 \\
\hline \multicolumn{5}{|c|}{ Physical activity } \\
\hline Mild & $2.3 \pm 2.2$ & $1.2 \pm 1.2$ & $32(23.0)$ & $3.1 \pm 2.6$ \\
\hline Moderate & $1.9 \pm 1.9$ & $1.4 \pm 1.4$ & $51(19.0)$ & $3.2 \pm 2.3$ \\
\hline Vigorous & $2.6 \pm 2.5$ & $1.5 \pm 1.7$ & $46(28.8)$ & $3.7 \pm 2.6$ \\
\hline$P$ value & 0.01 & 0.2 & 0.06 & 0.03 \\
\hline \multicolumn{5}{|c|}{ Body mass index } \\
\hline Underweight & $2.0 \pm 2.0$ & $1.3 \pm 1.2$ & 7 (15.6) & $3.2 \pm 3.4$ \\
\hline Normal & $2.2 \pm 2.3$ & $1.3 \pm 1.4$ & $82(20.9)$ & $3.4 \pm 2.3$ \\
\hline Overweight & $2.4 \pm 2.5$ & $1.5 \pm 1.5$ & $40(30.5)$ & $3.2 \pm 2.5$ \\
\hline$P$ value & 0.5 & 0.5 & 0.04 & 0.7 \\
\hline
\end{tabular}

‡ Analysis of variance.

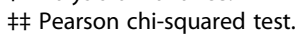

† Consumption of five servings a day.

$f$ Grams of ethanol per week. 


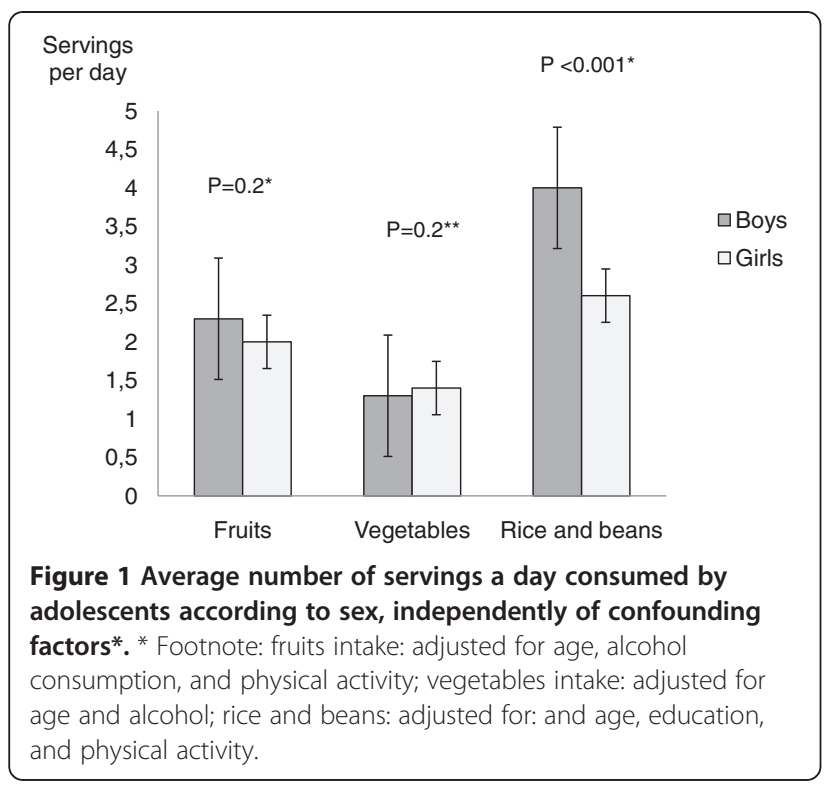

The direct associations between socioeconomic status and consumption of fruits and vegetables or five-a-day detected in previous studies [10,13,14,35-37] were based on income or the education of a family member. In this study, instead, we evaluated the education of the adolescent. Since they have a small range of years at school, the association did not reach statistical significance. The association between age and intake of some food groups have been reported $[7,38,39]$ and accounted for the inclusion of age as a confounding factor in this study.

The association between vigorous physical activity and higher intake of fruits seems to be part of positive habits in the adolescent's lifestyle [40], which might be clustered with other healthy behaviors such as lower rate of smoking [41]. Even so, it was detected an association between overweight and five-a-day intake. This association

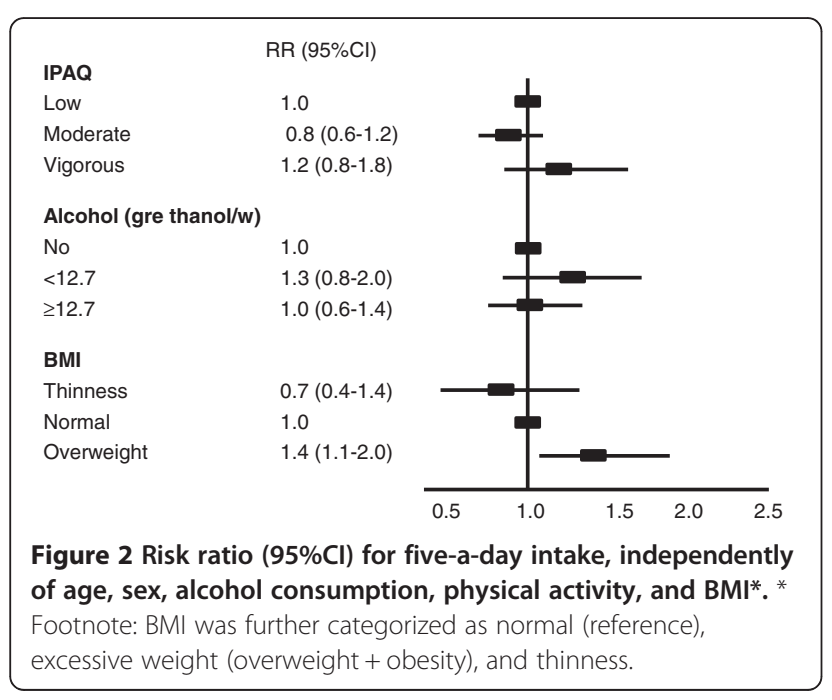

could reflect that those adolescents eat more everything, including fruits and vegetables, or even that those who have the higher BMI are eating more fruit and vegetables because they are trying to lose weight. The crosssectional design does not preclude reverse causality as a potential explanation for this finding.

This study has other limitations that deserve to be mentioned. The food intake was estimated by a FFQ over a twelve months period, and specific questions were asked regarding fruits and vegetables consumption in the 24 hours before the interview. Even both instruments being susceptible to biases, they were validated for adolescents from southern Brazil [27] in the Syndrome of Obesity and Risk Factors for Cardiovascular Disease (SOFT) study. In addition, portion size varies according to the participant and the population setting. Data from the EPIC-Norfolk study have demonstrated a discrepancy in portion sizes for different fruits and vegetables, being the servings of fruits usually greater but vegetables smaller than 80 grams [42]. This value is close to an averaged serving of fruits and vegetables. Considering that frequency of intake could be more important than the serving size, to classify individuals as having a minimum intake of 400 grams of fruits and vegetables per day, these potential biases are not likely to affect the results.

A systematic review of the effectiveness of the program of five-a-day identified an increase from 0.1 to 1.4 servings per day in a setting of primary prevention [43]. Adolescents from Southern Brazil already have that average consumption of fruits and vegetables, suggesting that the target program's five-a-day can be more easily achieved. In addition to increasing consumption of fruits and vegetables, young people should be informed that rice and beans are not part of five servings per day. Finally, the diversity of fruits and vegetables can be an advantage to be explored in a five-a-day program.

In conclusion, adolescents from southern Brazil have a low frequency of five servings a day of combined fruits and vegetables. The detailed description of the current pattern of diet by adolescent may guide a strategy to recommend five-a-day in the country. The data about adolescents from developing countries helps to fulfill a gap on intake of fruits and vegetables. Our study provides information for adolescents from a representative population-based sampling from southern Brazil, and dietary intake was acquired through rigorous epidemiological methodology.

\section{Abbreviations}

Five-a-day: Five servings of fruits and vegetables per day, with or without rice and beans; Five-a-day - the color way: Five different servings of fruits and vegetables per day, with or without rice and beans; IPAQ: International Physical Activity Questionnaire; BMl: Body mass index; FFQ: Food frequency questionnaire; SOFT study: Syndrome of Obesity and Risk Factors for Cardiovascular Disease. 


\section{Competing interests}

None of the author has competing interests to declare.

\section{Authors' contributions}

MAR, MBM, LBM, FDF and SCF took part in the design, statistical analysis, and writing the manuscript. SCF conceived and coordinated the SOFT study. All authors read and approved the final manuscript.

\section{Acknowledgements}

This study was supported by grants and scholarships from the CNPq (National Council for Scientific and Technological Development), CAPES (Coordination for the Improvement of Higher Education Personnel), Fundação de Amparo a Pesquisa do Rio Grande do Sul (FAPERGS), and FIPEHCPA (Fundo de Apoio a Pesquisa, Hospital de Clínicas de Porto Alegre). The sponsors did not take part in the design or conduct of the study, including data collection, management, analysis, and interpretation of the data; and preparation, review, or approval of the manuscript. The authors had full access to all of the data in the study and take responsibility for the integrity of the data and the accuracy of the data analysis.

\section{Author details}

${ }^{1}$ Cardiolab-Hypertension, Hospital de Clínicas de Porto Alegre. Ramiro Barcelos 2350, Centro de Pesquisa Clínica, CEP 90035-003, Porto Alegre, RS, Brazil. ${ }^{2}$ Postgraduate Studies Program in Cardiology, School of Medicine, Universidade Federal do Rio Grande do Sul, Ramiro Barcelos 2600, CEP 90035-003, Porto Alegre, RS, Brazil. ${ }^{3}$ Division of Cardiology, and the National Institute for Science and Technology for Health Technology Assessment (IATS/CNPq). Hospital de Clínicas de Porto Alegre, Ramiro Barcelos 2350, Centro de Pesquisa Clínica, Cardiolab-Hipertensão, CEP 90035-003, Porto Alegre, RS, Brazil. ${ }^{4}$ Centro de Pesquisa Clínica, $5^{\circ}$ andar, Hospital de Clínicas de Porto Alegre, Universidade Federal do Rio Grande do Sul, Ramiro Barcellos, 2350, 90.035-003, Porto Alegre, RS, Brazil.

Received: 15 December 2011 Accepted: 8 November 2012 Published: 16 November 2012

\section{References}

1. Wang Y, Lobstein T: Worldwide trends in childhood overweight and obesity. Int J Pediatr Obes 2006, 1:11-25.

2. Ji CY, Cheng TO: Epidemic increase in overweight and obesity in Chinese children from 1985 to 2005. Int J Cardiol 2009, 132:1-10.

3. Kumanyika SK, Obarzanek E, Stettler N, Bell R, Field AE, Fortmann SP, Franklin BA, Gillman MW, Lewis CE, Poston WC 2nd, Hong Y, Stevens J, American Heart Association Council on Epidemiology and Prevention, Interdisciplinary Committee for Prevention: Population-based prevention of obesity: the need for comprehensive promotion of healthful eating, physical activity, and energy balance: a scientific statement from American Heart Association Council on Epidemiology and Prevention, Interdisciplinary Committee for Prevention (formerly the expert panel on population and prevention science). Circulation 2008, 118:428-464.

4. Ogden CL, Carroll MD, Flegal KM: High body mass index for age among US children and adolescents, 2003-2006. JAMA 2008, 299:2401-2405.

5. Instituto Brasileiro Geografia e Estatística: POF 2008-2009 - Antropometria e estado nutricional de crianças, adolescentes e adultos no Brasil. http://www.ibge.gov.br/home/presidencia/noticias/noticia_visualiza.php? id_noticia=1699\&id_pagina=1.

6. Bowman SA, Gortmaker SL, Ebbeling CB, Pereira MA, Ludwig DS: Effects of fast-food consumption on energy intake and diet quality among children in a national household survey. Pediatrics 2004, 113:112-118.

7. Ludwig DS, Peterson KE, Gortmaker SL: Relation between consumption of sugar-sweetened drinks and childhood obesity: a prospective, observational analysis. Lancet 2001, 357:505-508.

8. Berkey CS, Rockett HR, Field AE, Gillman MW, Colditz GA: Sugar-added beverages and adolescent weight change. Obes Res 2004, 12:778-788.

9. Nielsen SJ, Siega-Riz AM, Popkin BM: Trends in food locations and sources among adolescents and young adults. Prev Med 2002, 35:107-113.

10. Neumark-Sztainer D, Story M, Resnick MD, Blum RW: Correlates of inadequate fruit and vegetable consumption among adolescents. Prev Med 1996, 25:497-505.
11. Guenther PM, Dodd KW, Reedy J, Krebs-Smith SM: Most Americans eat much less than recommended amounts of fruits and vegetables. J Am Diet Assoc 2006, 106:1371-1379.

12. Neumark-Sztainer D, Wilson DB, Nietert PJ: Patterns of fruits, vegetables, and milk consumption among smoking and nonsmoking female teens. Am J Prev Med 2002, 22:240-246.

13. Pate RR, Heath GW, Dowda M, Trost SG: Associations between physical activity and other health behaviors in a representative sample of US adolescents. Am J Public Health 1996, 86:1577-1581.

14. Pronk NP, Anderson LH, Crain AL, Martinson BC, O'Connor PJ, Sherwood NE, Whitebird RR: Meeting recommendations for multiple healthy lifestyle factors. Prevalence, clustering, and predictors among adolescent, adult, and senior health plan members. Am J Prev Med 2004, 27:25-33.

15. Thomson CA, Ravia J: A systematic review of behavioral interventions to promote intake of fruit and vegetables. J Am Diet Assoc 2011, 111:1523-1535.

16. Diet nutrition and the prevention of chronic diseases. Report of a joint FAO/ WHO Expert Consultation. Geneva: World Health Organization; 2003. WHO Technical Report Series, no. 916

17. Subar AF, Heimendinger J, Patterson BH, Krebs-Smith SM, Pivonka E, Kessler $R$ : Fruit and vegetable intake in the United States: the baseline survey of the Five-a-day for Better Health Program. Am J Health Promot 1995, 9:352-360.

18. Brasil. Ministério da Saúde. Secretaria de Atenção à Saúde. Coordenação-Geral da Política de Alimentação e Nutrição. Guia alimentar para a população brasileira: promovendo a alimentação saudável/Ministério da Saúde, Secretaria de Atenção à Saúde, Coordenação-Geral da Política de Alimentação e Nutrição. Brasília: Ministério da Saúde; 2006:210 http://189.28.128.100/nutricao/docs/geral/10passosAdolescentes.pdf.

19. Stables GJ, Subar AF, Patterson BH, Dodd K, Heimendinger J, Van Duyn MA, Nebeling $L$ : Changes in vegetable and fruit consumption and awareness among US adults: Results of the 1991 and 19975 A Day for Better Health Program surveys. J Am Diet Assoc 2002, 102:809-817.

20. Ledoux TA, Hingle MD, Baranowski T: Relationship of fruit and vegetable intake with adiposity: a systematic review. Obes Rev 2011, 12:e143-e150.

21. Centers for Disease Control and Prevention: Prevalence of current cigarette smoking among adults and changes in prevalence of current and some day smoking--United States, 1996-2001. JAMA 2003, 289:2355-2356.

22. Moreira LB, Fuchs FD, Moraes RS, Bredemeir M, Cardozo S, Fuchs SC, Victora CG: Alcoholic beverage consumption and associated factors in Porto Alegre, a southern Brazilian city: a population-based survey. J Stud Alcohol 1996, 57:253-259.

23. Guidelines for Data Processing and Analysis of the International Physical Activity Questionnaire (IPAQ) - Short and Long Forms. 2005 https://docs.google.com/viewer?a=v\&pid=sites\&srcid= ZGVmYXVsdGRvbWFpbnx0aGVpcGFxfGd4OjEONDgxMDk3NDU1YWRIZTM

24. Cole TJ, Bellizzi MC, Flegal KM, Dietz WH: Establishing a standart definition for child overweight and obesity worldwide: international survey. BMJ 2000, 320:1-6.

25. Cole TJ, Freeman JV, Preece MA: British 1990 growth reference centiles for weight, height, body mass index and head circumference fitted by maximum penalized likelihood. Stat Med 1998, 17:407-429.

26. Cole TJ, Flegal KM, Nicholls D, Jackson AA: Body mass index cut offs to define thinness in children and adolescents: international survey. BMJ 2007, 335:194.

27. Henn RL, Fuchs SC, Moreira LB, Fuchs FD: Development and validation of a food frequency questionnaire (FFQ-Porto Alegre) for adolescent, adult and elderly populations from Southern Brazil. Cad Saude Publica 2010, 26:2068-2079.

28. Philippi ST: Brazilian food pyramid. Nutrition Today 2005, 40:79-83.

29. Neumark-Sztainer D, Story M, Hannan P, Moe J: Overweight status and eating patterns among adolescents: where do youth stand in comparison to the Healthy People 2010 Objectives? Am J Public Health 2002, 92:844-851.

30. Albert PL, Rivas JB, Dehollain JP, Blano R: Consumo de frutas y hortalizas em adolescents de un colegio privado de Caracas, Venezuela. An Venez Nutr 2002, 15:18-24.

31. Leal GV, Philippi ST, Matsudo SM, Toassa EC: Food intake and meal patterns of adolescents, São Paulo, Brazil. Rev Bras Epidemiol 2010, 13:457-467. 
32. Vítolo MR, Campagnolo PDB, Gama CM: Factors associated with risk of low dietary fiber intake in adolescents. J Pediatr 2007, 83:47-52.

33. Heimendinger J, Van Duyn MA, Chapelsky D, Foerster S, Stables G: The national 5 A Day for Better Health Program: a large-scale nutrition intervention. J Public Health Manag Pract 1996, 2:27-35.

34. Chiolero A, Madeleine G, Gabriel A, Burnier M, Paccaud F, Bovet P: Prevalence of elevated blood pressure and association with overweight in children of a rapidly developing country. J Hum Hypertens 2007 , 21:120-127.

35. Aounallah-Skhiri H, El Ati J, Traissac P, Ben Romdhane H, Eymard-Duvernay S, Delpeuch F, Achour N, Maire B: Blood pressure and associated factors in a North African adolescent population. A national cross-sectional study in Tunisia. BMC Public Health 2012, 12:98.

36. Marchioni DM, Claro RM, Levy RB, Monteiro CA: Patterns of food acquisition in Brazilian households and associated factors: a populationbased survey. Public Health Nutr 2011, 14:1586-1592.

37. Riediger ND, Shooshtari S, Moghadasian MH: The influence of socio-demographic factors on patterns of fruit and vegetable consumption in Canadian adolescents. J Am Diet Assoc 2007, 107:1511-1518.

38. US Department of Agriculture. Agricultural Research Service. Community Nutrition Research Group: Pyramid servings intakes in the United States 1999-2002, 1 day. http://www.ars.usda.gov/sp2UserFiles/Place/12355000/ foodlink/ts1-0.pdf.

39. Lien N, Lytle LA, Klepp KI: Stability in consumption of fruit, vegetables, and sugary foods in a cohort from age 14 to age 21. Prev Med 2001, 33:217-226.

40. Fernandes RA, Christofaro DG, Casonatto J, Kawaquti SS, Ronque ER, Cardoso JR, Freitas Júnior IF, Oliveira AR: Cross-sectional association between healthy and unhealthy food habits and leisure physical activity in adolescents. J Pediatr 2011, 87:252-256.

41. Larson NI, Story M, Perry CL, Neumark-Sztainer D, Hannan PJ: Are diet and physical activity patterns related to cigarette smoking in adolescents? Findings from Project EAT. Prev Chronic Dis 2007, 4:A51.

42. Ashfield-Watt PA, Welch AA, Day NE, Bingham SA: Is 'five-a-day' an effective way of increasing fruit and vegetable intakes? Public Health Nutr 2004, 7:257-261.

43. Pomerleau J, Lock K, Knai C, McKee M: Interventions designed to increase adult fruit and vegetable intake can be effective: a systematic review of the literature. J Nutr 2005, 135:2486-2495.

doi:10.1186/1475-2891-11-95

Cite this article as: Rieth et al:: Fruits and vegetables intake and characteristics associated among adolescents from Southern Brazil. Nutrition Journal 2012 11:95.

\section{Submit your next manuscript to BioMed Central and take full advantage of:}

- Convenient online submission

- Thorough peer review

- No space constraints or color figure charges

- Immediate publication on acceptance

- Inclusion in PubMed, CAS, Scopus and Google Scholar

- Research which is freely available for redistribution

Submit your manuscript at www.biomedcentral.com/submit
C Biomed Central 